\title{
rDNA sequence analyses of Streptococcus dysgalactiae subsp. equisimilis isolates from pigs
}

\author{
Correspondence \\ Koji Kawata \\ kawako@rakuno.ac.jp
}

\author{
Koji Kawata, ${ }^{1}$ Taichi Minakami, ${ }^{1}$ Yukari Mori, ${ }^{1}$ Masanori Katsumi, ${ }^{2}$ \\ Yasushi Kataoka, ${ }^{3}$ Ayako Ezawa, ${ }^{1}$ Naoya Kikuchi ${ }^{1}$ \\ and Tatsuhumi Takahashi ${ }^{1}$ \\ ${ }^{1}$ Department of Epizootiology, School of Veterinary Medicine, Rakuno Gakuen University, \\ Ebetsu, Hokkaido 069-8501, Japan \\ ${ }^{2}$ Sendai Meat Inspection Center, Sendai, Miyagi 983, Japan \\ ${ }^{3}$ Department of Veterinary Microbiology, Nippon Veterinary and Animal Science University, \\ Musashino, Tokyo 180, Japan
}

\section{INTRODUCTION}

The species Streptococcus dysgalactiae is known to include a variety of strains that are biochemically and genetically very close but differ in serological grouping, type of haemolysis, host association and pathogenicity (Jones, 1980; Farrow \& Collins, 1984; Kilpper-Bälz \& Schleifer, 1984; Hommez et al., 1991; Efstratiou et al., 1994; Bert et al., 1997). Vandamme et al. (1996) showed that these bacteria could be divided into two subspecies ( $S$. dysgalactiae subsp. dysgalactiae and S. dysgalactiae subsp. equisimilis) based on their whole-cell protein profiles and biochemical properties. Recently, Vieira et al. (1998) proposed a new classification for the organisms based on multilocus enzyme electrophoresis typing and genomic DNA relatedness. These analyses defined $\alpha$-haemolytic or non-haemolytic strains of Lancefield group C as $S$. dysgalactiae subsp. dysgalactiae and $\beta$-haemolytic strains of group C, G or L antigen as S. dysgalactiae subsp. equisimilis. This is the traditional and

Published online ahead of print on 20 June 2003 as DOI 10.1099/ ijs.0.02666-0.

The GenBank/EMBL/DDBJ accession numbers for the 16S and 23S rDNA sequences determined in this paper are given in Fig. 2. most widely used method of classification to date. Furthermore, genealogical divergences between $S$. dysgalactiae isolates have also been detected by means of multilocus enzyme electrophoresis (Bert et al., 1995), random amplified polymorphic DNA (RAPD) (Bert et al., 1996) and 16S-23S rRNA gene (rDNA) intergenic spacer analyses (Chanter et al., 1997).

The phylogenetic position of the species S. dysgalactiae within the genus Streptococcus has been estimated by sequencing analyses of 16S rRNA (Bentley et al., 1991; Kawamura et al., 1995a, b). However, subspecific information for sequences of $S$. dysgalactiae strains is limited and, therefore, the details of the phylogenetic relationship among strains of the organism remain unclear.

It is evident that the resolving power of $16 \mathrm{~S} \mathrm{rDNA}$ sequences is limited when closely related organisms are examined (Rogall et al., 1990; Amann et al., 1992; Fox et al., 1992), although analysis based on such sequences is a valuable phylogenetic marker, as is DNA reassociation (Stackebrandt \& Goebel, 1994). On the other hand, $23 \mathrm{~S}$ rRNA is about twice as long as 16S rRNA and contains more variable regions. Therefore, $23 \mathrm{~S}$ rRNA is considered to be a more 
informative phylogenetic marker (Ludwig \& Schleifer, 1999).

S. dysgalactiae subsp. equisimilis is classified into four subgroups of host-associated ecovars based on serogrouping and biotyping: human groups $\mathrm{C}$ and $\mathrm{G}$, animal group $\mathrm{C}$ and group L (Devriese, 1991). Bacteria of the latter two groups are frequently isolated from pigs, in which the organisms cause septicaemia, arthritis or valvular endocarditis (Hommez et al., 1991). In this study, we used porcine $S$. dysgalactiae subsp. equisimilis isolates associated with arthritis, lymphadenitis or valvular endocarditis to examine subspecific relationships among $S$. dysgalactiae strains through a comparison of the nucleotide sequences of their $16 \mathrm{~S}$ and $23 \mathrm{~S}$ rDNA.

\section{METHODS}

Bacteria. Streptococcal isolates and strains used for $16 \mathrm{~S}$ and $23 \mathrm{~S}$ rDNA analyses are shown in Table 1. Eleven porcine isolates of S. dysgalactiae subsp. equisimilis, whose origins have been described previously (Katsumi et al., 1997), were examined along with strain ATCC 35666 of $S$. dysgalactiae subsp. equisimilis and two strains of S. dysgalactiae subsp. dysgalactiae. In addition, Streptococcus agalactiae ATCC $13813^{\mathrm{T}}$ was used as an outgroup.

Phenotypic characterization. The Streptex agglutination procedure (Murex Diagnostics) was used for detection of the Lancefield group $\mathrm{A}-\mathrm{D}, \mathrm{F}$ and $\mathrm{G}$ antigens and the group $\mathrm{L}$ antigen was examined by precipitation in capillary tubes with hyperimmune serum (Lancefield, 1938). Streptokinase activity was determined on fibrinplasma plates as described previously (Vandamme et al., 1996).
DNA-DNA reassociation. DNA preparation and microplate hybridization were performed using the method of Ezaki et al. (1989) at an optimal renaturation temperature of $30{ }^{\circ} \mathrm{C}$ in $50 \%$ formamide.

Sequence determination of rDNA. Genomic DNA was extracted from bacterial colonies with a DNA extraction kit (SMITEST; Sumitomo Kinzoku Kogyo) according to the manufacturer's instructions. rDNA sequences were determined directly from DNA fragments produced by PCR amplification (Hultman et al., 1989, 1991). Primers and conditions for $16 \mathrm{~S}$ rDNA PCR were described previously (Takahashi et al., 1997). The $23 \mathrm{~S}$ rDNA sequence was analysed in the same manner. Furthermore, sequence determination was carried out for DNAs cloned into a pZero-2 vector plasmid (Invitrogen) for precise analysis. Oligonucleotide sequences of PCR primers used for the $23 \mathrm{~S}$ rDNA are listed in Table 2. These and most of the intergenic sequencing primers were designed on the basis of data from a streptococcal $23 \mathrm{~S}$ rDNA multiple alignment and sequences from previous investigations (Lane et al., 1991; Ash et al., 1992; Ludwig et al., 1992; Van Camp et al., 1993; Takahashi et al., 1997).

Denatured PCR fragments or recombinant plasmids were submitted to a sequencing reaction using an Auto-Read sequencing kit and an ALF Express II DNA sequencer (Amersham Pharmacia Biotech).

Sequence alignment, calculation of similarity values and phylogenetic tree construction. Nucleotide sequences of the $16 \mathrm{~S}$ and $23 \mathrm{~S}$ rDNA determined in this study were assembled and aligned manually using Gene Jockey II version 2.1 (Biosoft). Evolutionary distance values were estimated by Kimura's two-parameter method (Kimura, 1980) using the BioResearch SINCA program package (Fujitsu). The neighbour-joining method of Saitou \& Nei (1987) was employed to construct a phylogenetic tree using the BioResearch SINCA program. The topology of the tree was evaluated by a bootstrapping method (Felsenstein, 1985).

Table 1. Streptococci used for sequence analysis of $16 \mathrm{~S}$ and $23 \mathrm{~S}$ rDNA

S. dysgalactiae subsp. equisimilis strains are identified as arthritis-associated (prefix A), lymphadenitisassociated (L) or valvular endocarditis-associated (V) strains. NT, Not typable.

\begin{tabular}{|lccc|}
\hline Strain & $\begin{array}{c}\text { Type of haemolysis } \\
\text { on sheep blood }\end{array}$ & $\begin{array}{c}\text { Lancefield } \\
\text { group }\end{array}$ & $\begin{array}{c}\text { Streptokinase activity } \\
\text { on human plasminogen }\end{array}$ \\
\hline S. agalactiae ATCC $13813^{\mathrm{T}}$ & $\beta$ & $\mathrm{B}$ & Not tested \\
S. dysgalactiae subsp. dysgalactiae & $\alpha$ & $\mathrm{C}$ & $\mathrm{NT}$ \\
ATCC 43078 & & $\mathrm{C}$ & $\mathrm{NT}$ \\
ATCC 27957 & $\alpha$ & & + \\
S. dysgalactiae subsp. equisimilis & & $\mathrm{C}$ & - \\
ATCC 35666 & $\beta$ & $\mathrm{C}$ & - \\
A1 & $\beta$ & $\mathrm{L}$ & - \\
A7 & $\beta$ & $\mathrm{L}$ & - \\
A20 & $\beta$ & $\mathrm{C}$ & - \\
A24 & $\beta$ & $\mathrm{C}$ & - \\
L1 & $\beta$ & $\mathrm{C}$ & - \\
L2 & $\beta$ & $\mathrm{C}$ & - \\
L8 & $\beta$ & $\mathrm{L}$ & - \\
L21 & $\beta$ & $\mathrm{C}$ & - \\
L23 & $\beta$ & $\mathrm{C}$ & \\
V21 & $\beta$ & $\mathrm{C}$ & \\
V26 & $\beta$ & & \\
& & & \\
\hline
\end{tabular}


Table 2. Primers used for amplification of 235 rDNA

Primer positions are based on the E. coli numbering system (Brosius et al., 1981).

\begin{tabular}{|lllc|}
\hline PCR product & Primer & \multicolumn{1}{c|}{ Sequence $\left(\mathbf{5}^{\prime} \mathbf{- 3}^{\prime}\right)$} & Position \\
\hline Fragment 1 & Forward & GTACACACCGCCCGT & $1392-1406(16 \mathrm{~S})$ \\
& Reverse & GGGTTYCCCCATTCGG & $115-130$ \\
Fragment 2 & Forward & AAGGGCGCACGGTGGATGCC & $13-32$ \\
& Reverse & TTCTCCCGAAGTTACGG & $1685-1701$ \\
Fragment 3 & Forward & AAACCGACACAGGTAG & $1608-1623$ \\
& Reverse & CTTTTATCCGTTGAGCGA & $2419-2436$ \\
Fragment 4 & Forward & AGTTTGACTGGGGCGGT & $2241-2257$ \\
& Reverse & TTAACTTCCGTGTTCGGTATGGG & $36-58(5 S)$ \\
\hline
\end{tabular}

\section{RESULTS AND DISCUSSION}

The results of Lancefield grouping and streptokinase activity on human plasminogen of the 11 porcine isolates of S. dysgalactiae subsp. equisimilis are summarized in Table 1. Each of the isolates reacted with antibodies against the $\mathrm{C}$ or $\mathrm{L}$ antigen, which are considered to be the group antigens possessed by $S$. dysgalactiae subsp. equisimilis of animal origin. On the other hand, an atypical reaction was observed for streptokinase activity. Both Vieira et al. (1998) and Vandamme et al. (1996) have reported that a positive reaction for streptokinase activity on human plasminogen is a key characteristic for distinguishing subspecies equisimilis from subspecies dysgalactiae. However, the porcine isolates in this study did not exhibit streptokinase activity. These results were consistent with the results reported by Vandamme et al. (1996), in which most animal isolates of $S$. dysgalactiae lacked streptokinase activity, but were inconsistent with the classification proposed by Vieira et al. (1998). Streptokinase activity on human plasminogen may not be useful for identifying porcine isolates at the subspecies level as defined by Vieira et al. (1998).

Vieira et al. (1998) have reported that the levels of DNA relatedness between the two subspecies are $79 \%$ or less. However, the porcine isolates in this study showed high levels of DNA relatedness (85-88\%) against both $S$. dysgalactiae subsp. dysgalactiae and $S$. dysgalactiae subsp. equisimilis strains (Table 3 ). In this study, we tentatively designated the isolates as $S$. dysgalactiae subsp. equisimilis because of their $\beta$-haemolysis, which is a possible key factor for distinguishing one subspecies from the other based on the results reported by Vieira et al. (1998).

Alignment data from nucleotide residues 85 to 1500 (based on the Escherichia coli numbering system; Brosius et al.,

Table 3. DNA relatedness of porcine $S$. dysgalactiae strains against strains of the two subspecies of $S$. dysgalactiae

\begin{tabular}{|lcccc|}
\hline \multirow{2}{*}{ Source of unlabelled DNA } & \multicolumn{3}{c|}{$\begin{array}{c}\text { Relative binding (\%) } \\
\text { with labelled DNA from: }\end{array}$} \\
\cline { 2 - 5 } & \multicolumn{2}{c}{$\mathbf{2}$} & $\mathbf{6}$ & $\mathbf{1 2}$ \\
\hline 1. S. dysgalactiae subsp. dysgalactiae ATCC $43078^{\mathrm{T}}$ & 100 & $84 \cdot 1$ & $87 \cdot 0$ & $86 \cdot 4$ \\
2. S. dysgalactiae subsp. equisimilis ATCC 35666 & $80 \cdot 2$ & 100 & $86 \cdot 6$ & $86 \cdot 6$ \\
3. A1 & $87 \cdot 5$ & $84 \cdot 8$ & $84 \cdot 1$ & $92 \cdot 3$ \\
4. A7 & $86 \cdot 5$ & $84 \cdot 9$ & $85 \cdot 5$ & $82 \cdot 2$ \\
5. A20 & $85 \cdot 6$ & $86 \cdot 1$ & $85 \cdot 4$ & $87 \cdot 0$ \\
6. A24 & $85 \cdot 2$ & $87 \cdot 5$ & 100 & $81 \cdot 9$ \\
7. L1 & $84 \cdot 9$ & $84 \cdot 7$ & $87 \cdot 8$ & $81 \cdot 9$ \\
8. L2 & $86 \cdot 7$ & $85 \cdot 0$ & $87 \cdot 7$ & $86 \cdot 3$ \\
9. L8 & $85 \cdot 0$ & $87 \cdot 0$ & $81 \cdot 7$ & $86 \cdot 3$ \\
10. L21 & $86 \cdot 0$ & $85 \cdot 7$ & $88 \cdot 0$ & $83 \cdot 0$ \\
11. L23 & $88 \cdot 1$ & $86 \cdot 5$ & $84 \cdot 3$ & $91 \cdot 9$ \\
12. V21 & $84 \cdot 7$ & $88 \cdot 0$ & $88 \cdot 5$ & 100 \\
13. V26 & $85 \cdot 3$ & $85 \cdot 2$ & $87 \cdot 9$ & $83 \cdot 4$ \\
14. S. agalactiae ATCC $13813^{\mathrm{T}}$ & $19 \cdot 0$ & $22 \cdot 7$ & $17 \cdot 6$ & $17 \cdot 4$ \\
\hline
\end{tabular}




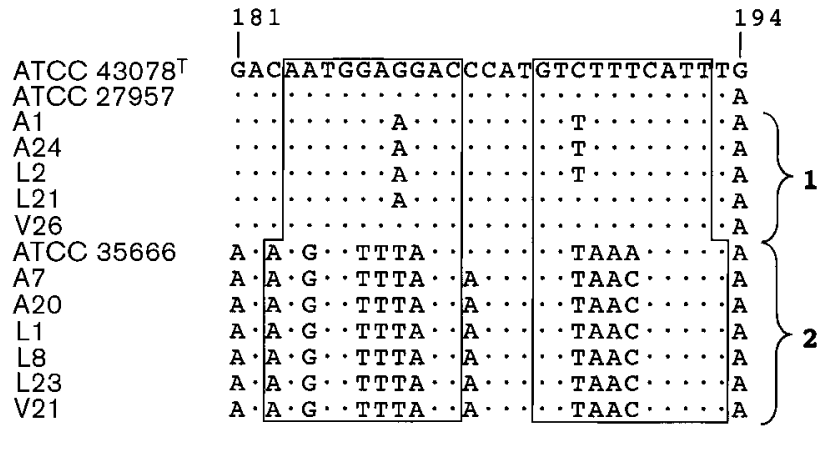

Fig. 1. Sequence alignment of residues 181-194 of the $16 \mathrm{~S}$ rDNA of strains of $S$. dysgalactiae subsp. dysgalactiae (ATCC $43078^{\top}$ and ATCC 27957) and S. dysgalactiae subsp. equisimilis (A1 to $\mathrm{V} 21$ ). Dots indicates bases identical to the residue of strain ATCC $43078^{\top}$. Numbers 1 and 2 on the right correspond to subgroups designated in this study. Boxed sequences may form a helix structure with a minimum of free energy. Numbering of positions follows the convention for $E$. coli (Brosius et al., 1981).

1981) of the $16 \mathrm{~S}$ rDNA were used for comparative analyses of the streptococcal strains. Of the 1429 bases of the $16 \mathrm{~S}$ rDNA, nucleotide changes within the species $S$. dysgalactiae were found at 24 residues. Thirteen of the 24 residues were located in variable region V3 (residues 179-220) designated by Raué et al. (1990) and the others were scattered in and around the other variable regions.

Fig. 1 shows part of the sequence alignment from residues 181 to 194 of the $16 \mathrm{~S}$ rDNA. This substantial domain provided a criterion for subdividing strains of $S$. dysgalactiae subsp. equisimilis into two subgroups. One consisted of strains V26, L21, A1, A24 and L2, which all have sequences similar to that of $S$. dysgalactiae subsp. dysgalactiae. The other group consisted of the rest of the organisms, which were similar to each other but distinct from the other strains. We hypothetically designated the former and the latter as subgroups 1 and 2 (Fig. 1). The predicted secondary structures of rRNA estimated from these sequences were hairpin loop motifs. Although the primary sequences were significantly different at residues 181-194, the hairpin loop motifs were very similar. All the motifs consisted of helices, 10 or $11 \mathrm{bp}$ in length, and a 4-base loop. Furthermore, the numbers of canonical and non-canonical base pairs were nearly identical in each.

In the complete $23 \mathrm{~S}$ rDNA sequences (2904 bp), 21 positions varied between strains of the species $S$. dysgalactiae. However, no significant differences were apparent except at residues 294 and 652. In strains of $S$. dysgalactiae subsp. dysgalactiae, the bases at these positions were $\mathrm{A}$ and $\mathrm{T}$, respectively, while, in most strains of $S$. dysgalactiae subsp. equisimilis, the bases were $\mathrm{G}$ and $\mathrm{A}$.

It is apparent from the results of the treeing analyses based on $16 \mathrm{~S}$ and $23 \mathrm{~S}$ rDNA (Fig. 2) that the species S. dysgalactiae was distinct from the type strain of $S$. agalactiae with large evolutionary distance values (divergence $2 \cdot 43-3 \cdot 45$ and $3 \cdot 27-3 \cdot 47 \%$, respectively). However, the branching order and the length of sublines within the $S$. dysgalactiae clusters were significantly different. S. dysgalactiae subsp. equisimilis strains were subdivided into two distinct clades in the $16 \mathrm{~S}$ rDNA tree. The subgroups were recovered in 99 or $74 \%$ of the bootstrapped trees. Furthermore, one of the subgroups (subgroup 1) formed a distinct clade with the strains of S. dysgalactiae subsp. dysgalactiae (bootstrap value of the group, $99 \%$ ). This conflicts with the degree of difference between the two subspecies of $S$. dysgalactiae demonstrated by DNA-DNA reassociation analysis (Vieira et al., 1998). Furthermore, the results based on 16S rDNA were inconsistent with those based on PFGE (Bert et al., 1997) and PAGE profiling of bacterial whole-cell proteins (Vandamme et al., 1996). These studies have shown no distinct groups within porcine isolates of $S$. dysgalactiae, although subtle differences, as in the biochemical properties of the isolates used in this study, were detected in individual strains.

In contrast, the subgroups produced by $16 \mathrm{~S}$ rDNA treeing analysis were not distinguishable in the $23 \mathrm{~S} \mathrm{rDNA}$ tree. All the sublines of $S$. dysgalactiae strains branched at positions that were much closer to each other in the $23 \mathrm{~S}$ rDNA tree (divergence, $0.39 \%$ or less) than in the $16 \mathrm{~S}$ rDNA tree (divergence, $1.51 \%$ or less), although each of the clusters of $S$. dysgalactiae subsp. dysgalactiae and $S$. dysgalactiae subsp. equisimilis was monophyletic (bootstrap values 92 and $69 \%$, respectively). Subspecies-specific nucleotide differences were found at not more than three residues, though these could distinguish the two strains of $S$. dysgalactiae subsp. dysgalactiae from the other strains with a high bootstrap value in the treeing analysis. These findings were not inconsistent with the classification shown by Vieira et al. (1998).

It has been demonstrated that phylogenetic trees constructed from $16 \mathrm{~S}$ and $23 \mathrm{~S}$ rDNA sequence data are generally congruent with each other (Höpfl et al., 1989; Ludwig \& Schleifer, 1994; Sallen et al., 1996; Ward et al., 2000). However, in this study, the phylogenetic relationship derived from $16 \mathrm{~S}$ rDNA analysis was not supported by the result of the 23S rDNA analysis. This indicated that phylogenetic trees derived from $16 \mathrm{~S}$ and $23 \mathrm{~S}$ rDNAs are not always in agreement at the intraspecific level and poses the question of which phylogenetic marker reflects the true relatedness. A DNA-DNA reassociation study (Vieira et al., 1998) clearly subdivided $S$. dysgalactiae strains into two subspecies, one of which ( $\beta$-haemolytic) reacts with Lancefield group $\mathrm{C}, \mathrm{G}$ or $\mathrm{L}$ antigen and is positive for streptokinase activity on human plasminogen. The coincidence of these properties, except for streptokinase activity, in the porcine isolates used in this study suggests that the $23 \mathrm{~S}$ rDNA analysis has an advantage over the $16 \mathrm{~S}$ rDNA in the case of these taxa.

The strains used in our study carried either Lancefield C or $\mathrm{L}$ antigen. However, these serogroups were unrelated 

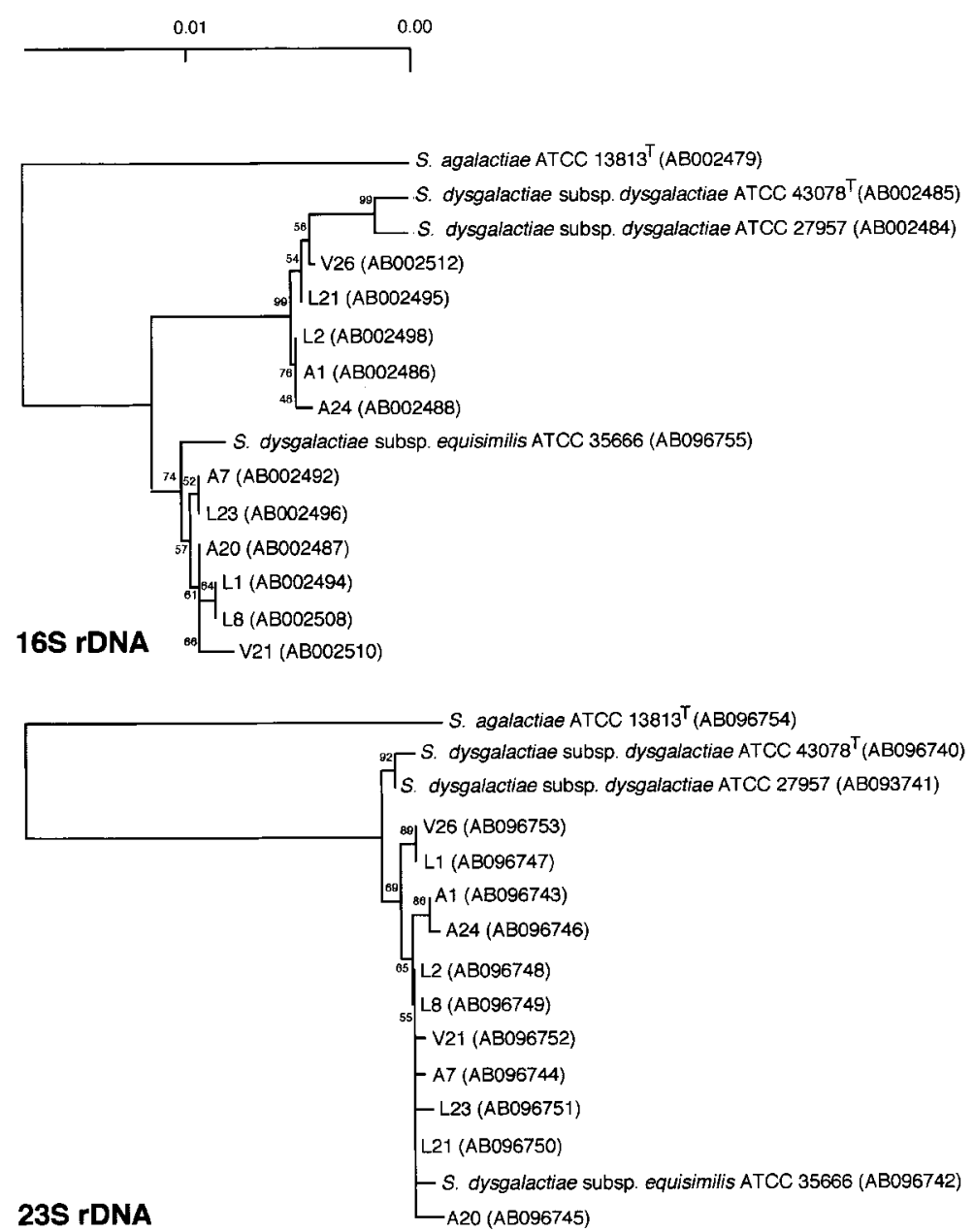

Fig. 2. Unrooted neighbour-joining trees based on 16S and 23S rDNA sequences of 12 strains of Streptococcus dysgalactiae subsp. equisimilis and two strains of $S$. dysgalactiae subsp. dysgalactiae. Numbers at nodes are estimated confidence levels expressed as percentages and determined by bootstrap analysis with 1000 replications. Bar, evolutionary distance $\left(K_{\text {nuc }}\right)$ between sequences, determined by measuring the lengths of horizontal lines connecting two organisms. to the phylogenetic relationships deduced from $16 \mathrm{~S}$ and $23 \mathrm{~S}$ rDNA sequences. Hommez et al. (1991) reported that Lancefield group C and L S. dysgalactiae from pigs have almost identical cultural and biochemical traits. Furthermore, it is nearly impossible to distinguish these S. dysgalactiae serogroups on the basis of genealogical analyses such as DNA-DNA hybridization (Farrow \& Collins, 1984), RAPD (Bert et al., 1996) and PFGE (Bert et al., 1997). These data indicate that distinctions based on Lancefield $\mathrm{C}$ or $\mathrm{L}$ serogrouping have no practical value for the subgrouping of $S$. dysgalactiae subsp. equisimilis.

The present phylogenetic analysis based on $16 \mathrm{~S}$ rDNA sequences indicates that two groups exist within $S$. dysgalactiae subsp. equisimilis of porcine origin and that this divergence does not seem to be related to the phylogenetic relationships of $23 \mathrm{~S}$ rDNA. Even so, the unique sequence found in the group-2 porcine isolates will be a useful marker for epidemiological studies.

Due to limitations in the number and source of strains examined, genealogical relationships between porcine strains of $S$. dysgalactiae subsp. equisimilis and other groups of strains, such as ecovars or group G strains, are still unclear.

\section{REFERENCES}

Amann, R. I., Lin, C., Key, R., Montgomery, L. \& Stahl, D. A. (1992). Diversity among Fibrobacter strains: towards a phylogenetic classification. Syst Appl Microbiol 15, 23-32.

Ash, C. \& Collins, M. D. (1992). Comparative analysis of $23 \mathrm{~S}$ ribosomal RNA gene sequences of Bacillus anthracis and emetic Bacillus cereus determined by PCR-direct sequencing. FEMS Microbiol Lett 94, 75-80.

Bentley, R. W., Leigh, L. A. \& Collins, M. D. (1991). Intrageneric structure of Streptococcus based on comparative analysis of smallsubunit rRNA sequences. Int J Syst Bacteriol 41, 487-494.

Bert, F., Picard, B., Lambert-Zechovsky, N. \& Goullet, P. (1995). Identification and typing of pyogenic streptococci by enzyme electrophoretic polymorphism. J Med Microbiol 42, 442-451.

Bert, F., Picard, B., Branger, C. \& Lambert-Zechovsky, N. (1996). Analysis of genetic relationships among strains of groups A, C and G streptococci by random amplified polymorphic DNA analysis. J Med Microbiol 45, 278-284.

Bert, F., Branger, C., Poutrel, B. \& Lambert-Zechovsky, N. (1997). Differentiation of human and animal strains of Streptococcus dysgalactiae by pulsed-field gel electrophoresis. FEMS Microbiol Lett 150, 107-112.

Brosius, J., Dull, T. J., Sleeter, D. D. \& Noller, H. F. (1981). Gene organization and primary structure of a ribosomal RNA operon from Escherichia coli. J Mol Biol 148, 107-127. 
Chanter, N., Collin, N., Holmes, N., Binns, M. \& Mumford, J. (1997). Characterization of the Lancefield group C streptococcus 16S-23S RNA gene intergenic spacer and its potential for identification and sub-specific typing. Epidemiol Infect 118, 125-135.

Devriese, L. A. (1991). Streptococcal ecovars associated with different animal species: epidemiological significance of serogroups and biotypes. J Appl Bacteriol 71, 478-483.

Efstratiou, A., Colman, G., Hahn, G., Timoney, J. F., Boeufgras, J. M. \& Monget, D. (1994). Biochemical differences among human and animal streptococci of Lancefield group C or group G. J Med Microbiol 41, 145-148.

Ezaki, T., Hashimoto, Y. \& Yabuuchi, E. (1989). Fluorometric deoxyribonucleic acid-deoxyribonucleic acid hybridization in microdilution wells as an alternative to membrane filter hybridization in which radioisotopes are used to determine genetic relatedness among bacterial strains. Int J Syst Bacteriol 39, 224-229.

Farrow, J. A. E. \& Collins, M. D. (1984). Taxonomic studies on streptococci of serological groups $\mathrm{C}, \mathrm{G}$ and $\mathrm{L}$ and possibly related taxa. Syst Appl Microbiol 5, 483-493.

Felsenstein, J. (1985). Confidence limits on phylogenies: an approach using bootstrap. Evolution 39, 783-791.

Fox, G. E., Wisotzkey, J. D. \& Jurtshuk, P., Jr (1992). How close is close: $16 \mathrm{~S}$ rRNA sequence identity may not be sufficient to guarantee species identity. Int J Syst Bacteriol 42, 166-170.

Hommez, J., Devriese, L. A., Castryck, F. \& Miry, C. (1991). $\beta$-Hemolytic streptococci from pigs: bacteriological diagnosis. $J$ Vet Med B 38, 441-444.

Höpfl, P., Ludwig, W., Schleifer, K. H. \& Larsen, N. (1989). The $23 \mathrm{~S}$ ribosomal RNA higher-order structure of Pseudomonas cepacia and other prokaryotes. Eur J Biochem 185, 355-364.

Hultman, T., Ståhl, S., Hornes, E. \& Uhlén, M. (1989). Direct solid phase sequencing of genomic and plasmid DNA using magnetic beads as solid support. Nucleic Acids Res 17, 4937-4946.

Hultman, T., Bergh, S., Moks, T. \& Uhlén, M. (1991). Bidirectional solid-phase sequencing of in vitro-amplified plasmid DNA. Biotechniques 10, 84-93.

Jones, J. E. T. (1980). Bacterial endocarditis in the pig with special reference to streptococcal endocarditis. J Comp Pathol 90, 11-28.

Katsumi, M., Kataoka, Y., Takahashi, T., Kikuchi, N. \& Hiramune, T. (1997). Bacterial isolation from slaughtered pigs associated with endocarditis, especially the isolation of Streptococcus suis. J Vet Med Sci 59, 75-78.

Kawamura, Y., Hou, X.-G., Sultana, F., Miura, H. \& Ezaki, T. (1995a). Determination of $16 \mathrm{~S}$ rRNA sequences of Streptococcus mitis and Streptococcus gordonii and phylogenetic relationships among members of the genus Streptococcus. Int J Syst Bacteriol 45, 406-408.

Kawamura, Y., Hou, X.-G., Sultana, F., Liu, S., Yamamoto, H. \& Ezaki, T. (1995b). Transfer of Streptococcus adjacens and Streptococcus defectivus to Abiotrophia gen. nov. as Abiotrophia adiacens comb. nov. and Abiotrophia defectiva comb. nov., respectively. Int J Syst Bacteriol 45, 798-803.

Kilpper-Bälz, R. \& Schleifer, K. H. (1984). Nucleic acid hybridization and cell wall composition of pyogenic streptococci. FEMS Microbiol Lett 24, 355-364.

Kimura, M. (1980). A simple method for estimating evolutionary rates of base substitutions through comparative studies of nucleotide sequences. J Mol Evol 16, 111-120.
Lancefield, R. C. (1938). A micro precipitin technique for classifying hemolytic streptococci, and improved methods for producing antisera. Proc Soc Exp Biol Med 38, 473-478.

Lane, D. J. (1991). 16S/23S rRNA sequencing. In Nucleic Acid Techniques in Bacterial Systematics, pp. 115-175. Edited by E. Stackebrandt \& M. Goodfellow. New York: Wiley.

Ludwig, W. \& Schleifer, K. H. (1994). Bacterial phylogeny based on $16 \mathrm{~S}$ and $23 \mathrm{~S}$ rRNA sequence analysis. FEMS Microbiol Rev 15, 155-173.

Ludwig, W. \& Schleifer, K. H. (1999). Phylogeny of Bacteria beyond the 16S rRNA standard. ASM News 65, 752-757.

Ludwig, W., Kirchhof, G., Klugbauer, N. \& 13 other authors (1992). Complete 23S ribosomal RNA sequences of Gram-positive bacteria with a low DNA G+C content. Syst Appl Microbiol 15, 487-501.

Raué, H. A., Musters, W., Rutgers, C. A., Van't Riet, J. \& Planta, R. J. (1990). rRNA: structure to function. In The Ribosome: Structure, Function and Evolution, pp. 217-235. Edited by W. E. Hill, A. Dahlberg, R. A. Garrett, P. B. Moore, D. Schlessinger \& J. R. Warner. Washington, DC: American Society for Microbiology.

Rogall, T., Wolters, J., Flohr, T. \& Böttger, E. C. (1990). Towards a phylogeny and definition of species at the molecular level within the genus Mycobacterium. Int J Syst Bacteriol 40, 323-330.

Saitou, N. \& Nei, M. (1987). The neighbor-joining method: a new method for reconstructing phylogenetic trees. Mol Biol Evol 4, 406-425.

Sallen, B., Rajoharison, A., Desvarenne, S., Quinn, F. \& Mabilat, C. (1996). Comparative analysis of $16 \mathrm{~S}$ and $23 \mathrm{~S}$ rRNA sequences of Listeria species. Int J Syst Bacteriol 46, 669-674.

Stackebrandt, E. \& Goebel, B. M. (1994). Taxonomic note: a place for DNA-DNA reassociation and $16 \mathrm{~S}$ rRNA sequence analysis in the present species definition in bacteriology. Int J Syst Bacteriol 44, 846-849.

Takahashi, T., Kaneko, M., Mori, Y., Tsuji, M., Kikuchi, N. \& Hiramune, T. (1997). Phylogenetic analyses of Staphylococcus based on the $16 \mathrm{~S}$ rDNA sequence and assignment of clinical isolates from animals. J Vet Med Sci 59, 775-783.

Van Camp, G., Chapelle, S. \& De Wachter, R. (1993). Amplification and sequencing of variable regions in bacterial $23 \mathrm{~S}$ ribosomal RNA genes with conserved primer sequences. Curr Microbiol 27, 147-151.

Vandamme, P., Pot, B., Falsen, E., Kersters, K. \& Devriese, L. A (1996). Taxonomic study of Lancefield streptococcal groups $C, G$, and $\mathrm{L}$ (Streptococcus dysgalactiae) and proposal of $S$. dysgalactiae subsp. equisimilis subsp. nov. Int J Syst Bacteriol 46, 774-781.

Vieira, V. V., Teixeira, L. M., Zahner, V., Momen, H., Facklam, R. R., Steigerwalt, A. G., Brenner, D. J. \& Castro, A. C. D. (1998). Genetic relationships among the different phenotypes of Streptococcus dysgalactiae strains. Int $J$ Syst Bacteriol $\mathbf{4 8}$, 1231-1243.

Ward, N. L., Rainey, F. A., Hedlund, B. P., Staley, J. T., Ludwig, W. \& Stackebrandt, E. (2000). Comparative phylogenetic analyses of members of the order Planctomycetales and the division Verrucomicrobia: $23 \mathrm{~S}$ rRNA gene sequence analysis supports the 16S rRNA gene sequence-derived phylogeny. Int J Syst Evol Microbiol 50, 1965-1972. 